\title{
Hotel Uniform Proposal for Jeju I
}

\author{
Sookhee Kwon ${ }^{\dagger}$ \\ Dept. of Clothing \& Textiles, Jeju National University; Jeju, Korea
}

\begin{abstract}
The purpose of this research is to propose employee uniforms for tourist hotels on Jeju Island, such uniforms that embrace Jeju's unique culture and promote the tourism of Jeju Island. It has been suggested that there exists a need for hotel employee uniforms to attract more tourist attention and boost Jeju's tourism industry. We designed the uniform after analyzing the empirical data collected from academia thesis, periodicals, papers and pictures from internet search, and fashion industry magazines. The uniform analysis and production procedures are as follows: (1) precedent research case review (2) current (existing) uniform status survey (3) latest fashion trend analysis (2010 - 2014) (4) creating the uniform implementing the trend-based design with Gal Cheon, Jeju's cultural product material. We found tipping points of the design through literature and trend analysis; we developed appropriate uniforms accordingly that are harmonious with Jeju's unique identity. We received great evaluations on the appearance and comfort as well. A new concept of uniform featuring Gal Cheon has been proposed. It is expected that the uniforms will promote the brand image of Jeju as an international freedom city and its culture.
\end{abstract}

Key words : Jeju's unique culture, symbol, Gal Cheon, hotel uniform, fashion trend

\section{Introduction}

Hotels in each region are paying much attention even to uniforms as international business is booming. Because uniforms represent the image of a hotel, a hotel's image is delivered and through this, corporation's image is uplifted and its PR activity is implemented actively. Appearance, uniform and behavior of hotel employees become an index informing a specific hotel and it was observed that a company has become a top business through relatively large amounts of investment in uniform, etc. In case of a hotel, uniform not only provide customers with the most prominent visual effect but also provides important impact in giving the first impression of the hotel to customers at decisive moment(Lennon \& Miller, 1984). As an important element providing impacts on potential interaction which gives the first impression of the hotel to customers, uniforms provide important impacts on formation of recognition as well as attitude of a hotel(Kang, 1995; Ryan, 1966). Poor uniforms make customers recognize images of a corporation as improper and low level(Laabs, 1995).

In reality, people want new changes of uniforms but they are still trapped in pre-modern perception in forms of uniforms compared to today's flow of fashion. This may be originated from unique limit of uniforms, misunderstanding of corporations' owners and

†Corresponding author; Sookhee Kwon

Tel. +82-64-754-3532, Fax. +82-64-725-2591

E-mail: sookhee@jejunu.ac.kr neglect of wearers of uniforms, etc.(Lee, 1991).

According to precedent researches which had implemented satisfaction investigations of uniforms(Lee \& Park, 2007), symbolism of uniform was recognized as relatively important and in particular, since uniforms of employees working at the front desk of a guestroom department is the most important part in delivering the hotel image, it was pointed out that uniforms are necessary as symbolic clothes. In each department, it was also said that it is necessary to consider about symbolism as positions of employees are higher.

Fashion industry has played a leading role in acceptance of tradition in clothes from an industrial dimension. Attempts in expressing its traditional nature were mainly limited to works through designer collections and exploration for possibility of application in uniforms which are worn among employees of international companies such as corporations or hotels mainly dealing with foreign countries or foreign people international is very minimal. If we visit a Japanese resort, 'Hosinoya Garuijawa', uniform designs of employees of lodging facility are very unique and special and it is said to be clothes of a famous designer which are very expensive (Lesile \& Nancy, 1998/2002). It is believed to be a strategy which expresses its unique symbolism of the region. Symbolism is expression of individuality that delivers differentiated images and also can be expression of business owners and employees.

Thus, in this research, we have carried out questionnaire survey for hotel employees in Jeju region. We tried to find out feasibility by asking about uniform made out of Gal Cheon as the main material which contains culture and emotion of Jeju in uniform design 
and to develop hotel uniforms that can differentiate the regional tradition. Gal Cheon of Jeju is natural dying clothes that permeate Jeju culture fully. At present, wellbeing and LOHAS, etc. are expanding as a trend and demand for environment friendly product is increasing rapidly. As natural dying has the functions of antibacterial and deodorizing, etc. it itself and also has emotional characteristics, a new market is being formed.

Recently, in Jeju, many conferences are held for MICE events and various other purposes, many tourists are visiting. Hotels located in international free city Jeju has a good location which can inform Jeju tradition not only to domestic tourists but also to foreign tourists. By attempting differentiation with existing uniforms, it will ultimately uplift images of hotels while employees have pride for their uniforms. We intend to contribute to induction of tourists and development of tourism industry of Jeju Island through uniforms with a new concept.

\section{Method}

We have analyzed precedent related researches for processing the research and also implemented questionnaire survey on uniforms with the object of employees of 10 hotels including special class hotels in Jeju city. For uniform designs, seasonal fashion trends between 2010 and 2014 were analyzed. After results of the questionnaire survey and trend analysis, the research was processed in the order of hotel uniform planning and development by reflecting the result.

\subsection{Object and period of the questionnaire survey}

This research has reviewed matters of uniform currently worn by employees working at hotels in Jeju region. We have surveyed about satisfaction, improvement, symbolism and tradition of uniforms and also asked in case when Gal Cheon was used for the uniforms. Objects of the survey were total 62 people who were above manager position among those who mainly worked over five years. The survey period was from February to June of 2013.

\subsection{Composition of the questionnaire}

Questionnaires used in this research were extracted from relevant questions of Yang's(2001) research with modification in compliance to the contents of this research. As shown in Table 1, it was composed of general matters regarding objects of the survey $(4$ questions), attitude about uniforms(3 questions), satisfaction on uniforms(4 questions) and preference(5 questions).

\subsection{Production of trial uniform}

We have used two kinds of Gal Cheon. One was dyed in per-
Table 1. Composition contents of the questionnaire

\begin{tabular}{|c|c|c|}
\hline Question index & Question contents & Number of question \\
\hline $\begin{array}{l}\text { General matters of the } \\
\text { objects of the survey }\end{array}$ & $\begin{array}{l}\text { Sex, career, working } \\
\text { department and age }\end{array}$ & 4 \\
\hline $\begin{array}{l}\text { Attitude } \\
\text { about uniform }\end{array}$ & $\begin{array}{l}\text { Attitude about uniform } \\
\text { wearers, distinction or } \\
\text { not with other hotels and } \\
\text { harmony with } \\
\text { department } \\
\text { characteristics }\end{array}$ &  \\
\hline $\begin{array}{l}\text { Satisfaction about } \\
\text { uniform }\end{array}$ & $\begin{array}{l}\text { Wearing satisfaction, } \\
\text { satisfaction about shapes } \\
\text { and colors, improvement } \\
\text { and satisfaction about } \\
\text { fabric }\end{array}$ & t \\
\hline $\begin{array}{l}\text { Preference } \\
\text { about uniform }\end{array}$ & $\begin{array}{l}\text { Feels about uniforms, } \\
\text { important matters when } \\
\text { deciding uniforms and } \\
\text { others }\end{array}$ & 5 \\
\hline
\end{tabular}

simmon dye after refining cotton(cotton $100 \%$, weight $115.08 / \mathrm{m}^{2}$, thickness $0.30 \mathrm{~m} / \mathrm{m}$, plain weave) and another used a little thick textile purchased from Galot specialty store(Gal jean: material which dyed denim in persimmon dye). Product Production period of trial uniform was from July 2013 to January 2014.

\section{Theoretical Background}

Uniform, as clothes directly explaining roles of wearers, makes wearers have identity within workplaces or organizations or indicates their positions and also delivers characteristics of workplaces or organizations externally. More than anything else, uniforms must be helpful in improving job performance or work efficiency for wearers. For successful implementation of a role of a job, the importance of clothes reflecting functional aspect as well as psychological aspect and fashion sense is being emphasized more and it was found out that consciousness about uniforms is changing(Kang, 1995).

In general, types of uniforms must be able to show images than a big change of the style itself and it must be a form without difficulty and neat costume so that uniforms comply to the characteristics of uniforms that many people wear the same clothes(Ko, 1982). In addition, colors used for uniforms shall give provide lucidity and clearness while giving sense of stability and images kept by the colors must comply with use and style of uniforms. Therefore, colors harmonizing with contents of works and environment of workplaces are required and must be selected in consideration of seasons and ages of wearers. Also, since uniforms are more often contaminated unlike usual clothes and must be washed 
often, uniforms need durability resisting well against friction, wear and tear, change and discoloring, etc. In addition, uniforms, which maintain shapes well without ironing after washing while easy to wash and dry, are preferred and in general, synthetic fibers are more used than natural fibers. On the other hand, in case of Regent Hotel in Hong Kong, uniforms of the employees are very elegant and luxurious and this is to provide a tangible clue of Regent Hotel which has symbolic image of gracefulness and professionalism(Chung, 2000). According to precedent researches (Lee \& Park, 2007), satisfaction about uniforms is indicated in the sequence of aesthetic, activity, symbolism and management.

Ryan(1966) said that design of clothes is composed of basic elements of line, shape, space, material and color but uniform design is composed of appearance, function and character due to its characteristics. Composition elements of uniforms reported in precedent researches are as follows.

\subsection{Appearance}

External appearance is a strong design element which decides the first impression and is the most important aspect in satisfaction of clothes. External appearance of clothes provides information of wearers such as social and professional position, role of sex, political inclination and aesthetic sense, etc. Nelson and Bowen(2000) said that in attributes of external appearance, there are color, material, fit and conspicuousness, etc.

Because color is the most complex and concurrently provocative among all elements of design, it delivers the most powerful message as a non-linguistic communication tool(Ryan, 1966). Since color has its unique character provided to specific color recognized by people, it provides personality and psychological clue of a wearer(Lee et al., 2003). Material is a design element generally related to contact sense. Therefore, because it is impossible to explain good and bad fibers only with visual experiences, it plays an important role of wearing feel. Fit must be able to provide freedom to behaviors. If uniform is loose or heavy, wearing employee cannot perform efficient job. Unfitting uniform degrades pride and it brings about results of lowering service quality for customers(Chung, 2000). Conspicuousness exists when there is no identity among different members of an organization. Conspicuousness is shown clearly when one is not with non-members of an organization. Level of conspicuousness distinguishes members and nonmembers of an organization and its level is classified as high, low and appropriate level and majority of hotel uniforms have high conspicuousness(Rafaeli \& Pratt, 1993). Because this high level of conspicuousness indicates clearly who will provide services to a customer, it can eliminate dissatisfaction of customers. Therefore, in hotels, uniforms provide big help in supplying tangible services expected by customers as customers can easily recognize employees and also can judge location of employees(Chung, 2000).

\subsection{Function}

Horn and Gruel(1981) wrote uniform is the most efficient which can show maximum effects of one's own job and for these functional attributes, there are material, durability, practicality and symbolism. Material is included not only in external element but also in functional element. Since hotel uniform must always maintain cleanness and neatness, it must have durability and also must be convenient for washing(Yang, 2001). Uniforms must be able to resist washing for a long time. Practicality is important in performing jobs efficiently and symbolism is expression of individuality that delivers differentiated images unique to a hotel as employees of a hotel corporation wear the unified uniforms. It also contains symbolism in which executives and employees can form a hotel corporation with expression of consciousness in unity. If uniform design of a certain hotel is wrong, not only the atmosphere of a product within a hotel, that is, guest room and unit business place but also the image of a hotel can become wrong. Like this, uniform is a face of a hotel and the spirit of unity is highlighted by making wearers to have sense of identity belonging to the same group. Employees will try in order to satisfy needs of customers by wearing uniforms reflecting value and identity of the organization they work for. Like this, non-linguistic clue provided by uniforms will reinforce competence of an organization that tries to provide customers with the best services(Lee et al., 2003).

\subsection{Character}

Uniforms for professions show various jobs and therefore, uniforms must comply to work environment with convenience and utility and also symbolize the authority. Like this, uniforms not only control behavior of individual in an organization while establishing their expectation and roles but also form expectation of other people. In characteristics of these uniforms, there are style, integrity, comfort and structure, etc.(Ryan, 1966). Style indicates status and power as a type of clothes expected or accepted and can be classified into formal wear and informal wear. While formal wear is clean, straight and accurate, informal wear gives casual feeling typically. Integrity is to have employees wearing uniforms play their own roles and for example, colorful uniform of a bellman of special class hotel is easily located and help customers find the bellman easily. Raw and vivacious costumes of Disneyland will mean a role of providing customers with fantasy and fun pursued by Disneyland. Comfort is an attribute that uniform definitely has to furnish. In case of a loose sleeve, movement of an arm is not free because it is easy to be stuck to something and too narrow skirt cab 
give lots of inconveniences often. Like this, inconvenient designs providing discomfort to department works affect negative impacts on job attitude of employees. Proper structure play a decisive role in convenience of uniforms. As results of examination, it was found out that fashion, aesthetics and symbolism of hotel uniforms are also very important.

\section{Results and discussion}

As analyzed in precedent researches, fashion and symbolism of hotel uniforms are considered more important as positions of employee are higher. This research has collected opinions of hotel employees who are working in Jeju city. We tried to develop hotel uniforms which are reflecting Jeju culture by analyzing the above results and trend changes for recent several years. Among uniforms per department of the hotels, we produced trial uniforms by limiting at forms of jacket, one-piece, vest and apron of female employees working at guest room department and front desk of the hotels. We have discussed about suggestion designs by exchanging opinions with students of clothing and textiles department of Jeju National University and also went through stages of implementing uniform planning and completion. We have designed so that onepiece and jacket match well and also designed vest which can be worn through various coordination and apron considering practicality and esthetics and have excluded blouses from the items as its frequency was low. In overall composition, it was because blouses could produce in brighter mood by using different material other than Gal Cheon materials which have more rigid and dark feeling. The questionnaire survey results are as follows.

\subsection{The questionnaire survey results about hotel uniforms within Jeju Island}

4.1.1 General matters about the objects of the survey

General matters of the objects of the survey were about sex, age, career and working departments as indicated in Table 2. The objects of this research were $59.7 \%$ of female and $40.3 \%$ of male. Age was the highest of $67.7 \%$ of employees who were $26 \sim 30$ years old. Career was $64.4 \%$ who worked $5 \sim 9$ years and it was the result of taking intentionally manager levels who were with relatively long period of working career. For working department, guest room department was the highest with $56.5 \%$.

\subsubsection{General attitude about uniforms}

Reviewing responses of employees about uniform wearing in Table 3, it shows a little negative response with $41.9 \%$ of 'comfortable' of uniform wearing and $48.4 \%$ of help to 'have sense of belonging to the workplaces'. It showed negative response by hav-
Table 2. General matters of the objects of the survey

\begin{tabular}{ccccc}
\hline Classification & & N(People) & $\%$ & Total \\
\hline \multirow{2}{*}{ Sex } & Male & 25 & 40.3 & \multirow{2}{*}{$62(100)$} \\
& Female & 37 & 59.7 & \\
\hline \multirow{3}{*}{ Age } & $21 \sim 25$ years old & 3 & 4.8 & \\
& 26 30 years old & 42 & 67.7 & \multirow{2}{*}{$62(100)$} \\
& $31 \sim 35$ years old & 10 & 16.2 & \\
& $36 \sim 40$ years old & 7 & 11.3 & \\
& $1 \sim 2$ years & 0 & 0 & \\
Career & $3 \sim 4$ years & 12 & 19.4 & \multirow{2}{*}{$62(100)$} \\
& $5 \sim 9$ years & 40 & 64.4 & \\
& Over 10 years & 10 & 16.2 & \\
\hline \multirow{2}{*}{ Working } & Guest room & 35 & 56.5 & \\
department & Management & 18 & 29.0 & $62(100)$ \\
& Food \& beverage & 9 & 14.5 & \\
\hline
\end{tabular}

Table 3. Attitude about wearing uniforms $\mathrm{n}(\%)$

Answer Yes No Total

Help to have pride in works doing now 28(45.2) 34(54.8) 62(100) Help to have sense of belonging to the workplaces

30(48.4) 32(51.6) 62(100)

Work efficiency is increasing

27(43.5) 35(56.5) 62(100)

Comfortable

26(41.9) 36(58.1) 62(100)

It may be good to change to different materials. (Gal Cheon or fashion material) 42(67.7) 20(32.3) 62(100)

ing $54.8 \%$ and $56.5 \%$ of no answers in 'help to have pride in works doing' and 'work efficiency is increasing'. As shown in Table 4, it was found out that improvement of uniform is necessary with answers of each $56.5 \%$ of 'average' and $27.4 \%$ of not harmony well in questions whether the currently wearing uniforms harmonize with the characteristics of departments they are working in. Also as desires for other different materials are high, it showed that employees were not very much satisfied with the current materials of their uniforms. On the other hand, with relatively high answers of $51.6 \%$ in 'no distinct with other hotels', it can be said that it is now time to require uniforms which can express unique images of each hotel. In question of differentiation of their current uniforms with other hotels, $51.6 \%$ answered no distinct and need differentiation and also answered that their uniforms do not harmonize with

Table 4. Attitude about the currently wearing uniforms

\begin{tabular}{cccc}
\hline Item & Frequency & $\mathrm{n}(\%)$ & Total \\
\hline $\begin{array}{c}\text { Distinction with } \\
\text { other hotels }\end{array}$ & Well distinct & $10(16.1)$ & \\
& Average & $20(32.3)$ & $62(100)$ \\
Hot well distinct & $32(51.6)$ & \\
Working department & Harmony well & $10(16.1)$ & \\
characteristics & Not harmony well & $17(27.4)$ & \\
\hline
\end{tabular}


Table 5. Satisfaction about uniforms currently wearing

\begin{tabular}{cccc}
\hline Frequency & $\mathrm{n}$ (People) & $\%$ & Total \\
\hline Satisfied & 12 & 19.3 & \\
Average & 11 & 17.7 & $62(100)$ \\
Need to improve & 33 & 53.3 & \\
Unnecessary & 6 & 9.7 & \\
\hline
\end{tabular}

the characteristics of their working departments.

\subsubsection{Satisfaction about uniforms}

As shown in Table 5, we can find out that level of dissatisfaction about uniforms is high as we can see $19.3 \%$ of low rate in 'satisfied' in hotel employees' satisfaction about uniforms while the opinion requiring, 'improvement' is high at $53.3 \%$. This was the same result in precedent researches of Lee(1991), Yang(2001) which showed higher rate for improvement. Reasons of higher rate of dissatisfaction about uniforms are believed to be because opinions and preferences of employees are not well reflected in developing and selecting employees' uniforms. Therefore, it is necessary to develop new uniforms by reflecting dissatisfaction and require-

Table 6. Things to be improved in the current uniforms

\begin{tabular}{llllll}
\hline & Item & Design Color & $\begin{array}{c}\text { Fabric } \\
\text { (material) }\end{array}$ & $\begin{array}{c}\text { Function } \\
\text { (activity) }\end{array}$ & Total \\
\hline $\mathrm{n}(\%)$ & $35(56.5)$ & $2(3.0)$ & $20(32.4)$ & $5(8.1)$ & $62(100)$ \\
\hline
\end{tabular}

ments of uniforms they are wearing now.

When asking about improvement of their current uniforms, as shown in Table 6, design was the highest at 56.5\% and dissatisfaction about material was also $32.4 \%$. They requested improvements in sequence of functionality(activity) and color.

As shown in Table 7, answers to a question of satisfaction on fabrics used for uniforms are inclined to 'Average' and 'Bad' and answers to questions of air permeability or sweat absorption were mostly bad. As answers about durability, elasticity and wrinkles were mainly 'no problem' and it was contrary to the results of dissatisfaction in previous Yang's(2001) research. It may be because functionality of materials have been improved a lot recently. However, in questions of electrostatic, air permeability and sweat absorption, most have answered to have problems just like the researches of Lee(1991), Shim(1992) and Yang(2001).

In Table 8 asking about opinions on the current uniforms, answers related to fabrics, design and working departments were suggested and on materials, despite repeated questions, they showed same answers and also for design, they wanted design with fashion. They also said that they like individualistic designs. In addition, they wanted to have uniforms which are not the same but have some uniqueness according to working departments. This is believed to be psychology of clothing that employees want identity

Table 7. Satisfaction about clothes material used for uniform $\mathrm{n}(\%)$

\begin{tabular}{|c|c|c|c|c|c|}
\hline Satisfaction & Character & Good & Average & $\mathrm{Bad}$ & Total \\
\hline Durability(Lifespan) & & $22(35.1)$ & $28(45.2)$ & $12(19.4)$ & $62(100)$ \\
\hline Elasticity & & $28(45.2)$ & $15(24.2)$ & $19(30.6)$ & $62(100)$ \\
\hline Electrostatic & & $10(16.1)$ & $25(40.4)$ & $27(43.5)$ & $62(100)$ \\
\hline Air permeability & & $15(24.2)$ & $16(25.8)$ & $31(50.0)$ & $62(100)$ \\
\hline Crease resistance(wrinkles) & & $25(40.3)$ & $30(48.4)$ & $7(11.3)$ & $62(100)$ \\
\hline Sweat absorption & & $20(32.3)$ & $15(24.2)$ & $27(43.5)$ & $62(100)$ \\
\hline
\end{tabular}

Table 8. Opinion about the current uniform wearing

\begin{tabular}{|c|c|c|c|c|c|}
\hline \multicolumn{2}{|c|}{ Classification } & Yes & No & Average & Total \\
\hline \multirow{6}{*}{$\begin{array}{l}\text { Clothes } \\
\text { fabric } \\
\text { (Material) }\end{array}$} & Easy for activity & $29(46.8)$ & $11(17.7)$ & $22(35.5)$ & $62(100)$ \\
\hline & Good air permeability & $15(24.2)$ & $31(50.0)$ & $16(25.8)$ & $62(100)$ \\
\hline & Easy to wash & $20(32.3)$ & 11(17.7) & $31(50.0)$ & $62(100)$ \\
\hline & No electrostatic & $10(16.2)$ & $27(43.5)$ & $25(40.3)$ & $62(100)$ \\
\hline & No wrinkles & $25(40.3)$ & $8(12.9)$ & $29(46.8))$ & $62(100)$ \\
\hline & Absorb sweat well & $20(32.3)$ & $27(43.5)$ & $15(24.2)$ & $62(100)$ \\
\hline \multirow{3}{*}{ Design } & - Fashion design & $18(29.0)$ & $37(59.7)$ & $7(11.3)$ & $62(100)$ \\
\hline & - Individualistic design having tradition and symbolism, & $12(19.4)$ & $30(48.4)$ & $20(32.3)$ & $62(100)$ \\
\hline & - Average design & $25(40.3)$ & $28(45.2)$ & $9(14.5)$ & $62(100)$ \\
\hline \multirow{3}{*}{$\begin{array}{l}\text { Special } \\
\text { character }\end{array}$} & - Different uniform per working departments, & $31(50.0)$ & $18(29.0)$ & $13(21.0)$ & $62(100)$ \\
\hline & - One and the same uniform, & 12(19.4) & $30(48.3)$ & $20(32.3)$ & $62(100)$ \\
\hline & - Overall same design but different colors or points per working departments & $35(56.5)$ & $17(27.3)$ & $10(16.2)$ & $62(100)$ \\
\hline
\end{tabular}


Table 9. Recognition about Gal Cheon n $(\%)$

\begin{tabular}{|c|c|c|c|c|}
\hline$\overline{\text { Contents }}$ & Yes & No & Don’t know & Total \\
\hline Gal Cheon is a symbol of Jeju. & $28(45.2)$ & $15(24.2)$ & 19(30.6) & $62(100)$ \\
\hline Uniform with Gal Cheon as the main material may have meaning. & $35(56.5)$ & $16(25.8)$ & 11(17.7) & $62(100)$ \\
\hline If you have one item you want to develop? & $\begin{array}{c}\text { Jacket } 20(32.3) \\
\text { Apron } 4(6.5)\end{array}$ & $\begin{array}{c}\text { One-piece } 12(19.4) \\
\text { Blouse } 3(4.8)\end{array}$ & $\begin{array}{l}\text { Vest } 15(24.2) \\
\text { Other } 8(12.8)\end{array}$ & $62(100)$ \\
\hline
\end{tabular}

and also individuality even in uniforms.

Regarding questions about Gal Cheon, 45.2\% have answered positively to a question of 'Gal Cheon is a symbol of Jeju' but answerers of don't know about Gal Cheon were as high as 30.6\%. $56.5 \%$ showed interests by answering meaningful on uniforms with $\mathrm{Gal}$ Cheon as the main material and when asked to state items they want, jacket was the highest at $40.3 \%$ followed by sequences of one-piece dress(19.4\%), vest(24.2\%), apron(6.5\%), blouse (4.8) and others.

\subsection{Galot (Clothes made of persimmon juice dyed} material) as Jeju cultural product

Advantages of products of persimmon juice dying, which is one of natural dying, are functional and hygienic performance ultraviolet rays interception effect, activity, hygiene, durability, air permeability, strong softness, waterproof, insect proof, antibacterial and antimicrobial, etc. Galot is an environment friendly product and a cultural product with strong indigenous nature of Jeju Island and with expansion of commercialism and market, it is expected that Galot can be recognized as an important fashion culture product of Jeju region and will provide various symbolic · social benefits related to succession of 'traditional culture and Jeju tourism souvenir, etc. Producing uniforms with Gal Cheon as the main material is one way of pursuing symbolism. As recent tourism trend is gradually changing from natural tourism to cultural tourism, culture of regional community is emerging as important tourism resources and the government became to have lots of interests in strategies commercializing cultural elements unique to local communities. In overseas, discussions on product strategy models or optimum production systems required for making developing country folklore clothes to enter into the world tourists or global market are being implemented centering on American scholars(Hong, 2000). As global fashion flow is focused on fashion theme and environment friendly factors such as ecology, ethnic, retro style, romantic and cultural return, Jeju folklore clothes, Galot gets good responses from the public and is commercialized in more luxurious product and now, it can be said that Galot is recognized of its uniqueness of the country or region because Galot contains cultural element of Korea or Jeju region.

\subsection{Fashion trend analysis during 2010 and 2015}

As results of the survey of fashion trend of female clothes during $\mathrm{S} / \mathrm{S}, \mathrm{F} / \mathrm{W}$ of $2010, \mathrm{~S} / \mathrm{S}, \mathrm{F} / \mathrm{W}$ of $2011, \mathrm{~S} / \mathrm{S}, \mathrm{F} / \mathrm{W}$ of $2012, \mathrm{~S} / \mathrm{S}, \mathrm{F} / \mathrm{W}$ of 2013, S/S, F/W of 2014 and S/S, F/W of 2015, there was a strong tendency for emphasizing ethnic emotion and natural atmosphere. Colors of various middle tone made by nature were used with pleasure and retro flavor was expressed like flow of water within flow of time. Together with light material and simple line, minimalism, modern and sport showed strong force for several years and there were lots of designs which gave points with details. The word of naturalistic environment friendly was emphasized in every season and womanhood with soft and graceful feel was also emphasized. Simple line and minimal silhouette and luxurious color blocking were accomplished and continuing environment friendly mind produces comfortable and practical atmosphere. In material, a little bit of stretch was added for pursuing comfort and practicality. More weight was put on materials which are natural while being upgraded gradually. Ecology trend of fashion appearing in all seasons is presumed as continuous interests in nature. Light materials are in strong force and through upgraded cotton and linen, environment friendly solid cotton, mix between materials and color blocking between materials, it is a trend aiming for natural feel. In summary, materials with natural texture such as linen and cotton, etc. and methods adding flaps with luxurious silk or chiffon or harmonizing frill are very prevailing and also express luxury(Fashionnet Korea).

\subsection{New hotel uniform planning and development}

Using standard size of 20s suggested in Size Korea, trial products of uniforms in forms of jacket, one piece, vest and apron were completed by implementing pattern design per item according to Jeon and Kwon (2000) style production method. As results of uniform survey of five hotels within Jeju Island, there was no big difference with hotel uniforms of other regions and feeling about tradition was not contained at all. In case when Gal Cheon was used as the main material, a problem of management was raised but those places prioritizing images per department have answered very positively and therefore, it is believed to be meaningful to 


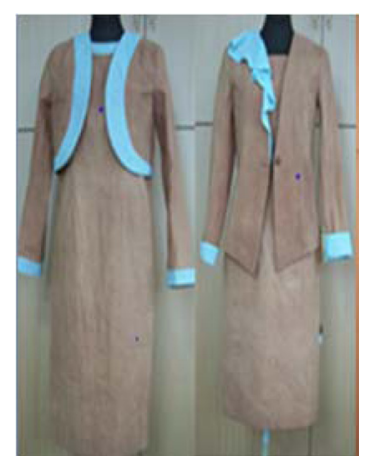

Fig. 1. Jacket \& one-piece dress (September 25, 2014).

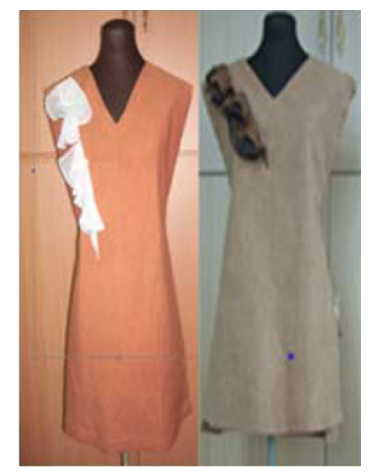

Fig. 2. Apron (September 25, 2014).

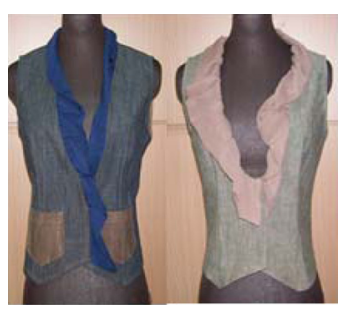

Fig. 3. Vest (September 25, 2014). develop Gal Cheon uniforms.

In order to add esthetics and fashion which are regarded as important in uniforms, trend analysis was applied. When we surveyed trend per seasons from 2010 to 2014, modern but minimal design continuously showed strong force and materials such as lace or chiffon were attached to fabrics or techniques applying to detailed parts such as sleeve tip or collar with ornaments of frill and ruffle, etc. were also referenced for uniform production.

As results of the questionnaire survey, preferred items wished to produce with Gal Cheon were in the sequence of jacket, one piece dress and vest. And according to the sequence, among uniforms of hotels, costume plan was established based on one piece, one piece and jacket type vest and apron in consideration of a fashion trend by limiting to clothes of female employees of guest room department and the products were finished. Materials providing points were decided by regarding the harmony with Gal Cheon and also were set to be able to arrange in various colors. Departments may be possible to be distinguished according to colors of fabrics with arrangement of colors. Color arrangement design was attempted in detail parts by referring to the trend. Development items products within the scope of the research with objects of female employees' uniforms of hotel guest room department or the front desk are like.

When designing patterns for activity nature of Galot, we have considered about surplus and opening. Figures(Fig. 1, Fig. 2 and Fig. 3) were taken during production time.

\section{Conclusion}

We tried to suggest a new concept of uniform through the questionnaire survey of relevant persons of hotels in Jeju region. There are 56 hotels in Jeju city and 61 hotels in Seogwipo city and we have surveyed around 10 hotels with easy accessibility. Just like precedent research results, inclination for requiring differentiation, fashion and estheticism in the currently wearing hotel uniforms was also found out in the survey results. They showed relatively positive responses on uniforms complementing symbolism of the hotels they are working in and also showed relatively good responses for $\mathrm{Gal}$ Cheon uniforms which can realize symbolism of their uniforms. In addition, it is believed to be necessary to reflect the trend survey in developing new uniforms because of desires for fashion and discomfort of materials of their current uniforms which were found out in the questionnaire survey results. We have produced a total of eight trial products of two jackets, two one-piece dresses two vests and two aprons uniforms which female employees of guest room department and front desk will wear through actual products planning based on the questionnaire survey results.

1. Just like precedent research results, it was found out in this survey result that employees want designs considering fashion in their current uniforms. For fashion survey, we have referred to trend survey per seasons from 2010 to 2014 and in the fashion trend suggested during the period, keywords of eco-friendly, natural, cotton, minimal, ecology, ethnic, material mix, frill and ruffle, etc. were appearing. Gal Cheon has lots of advantages as environment-friendly material unique to Jeju and is already evaluated as beautiful and comfortable material but because Gal Cheon has limits as materials of uniforms, it must be designed comfortably in structural aspect. Galot is advantageous in comfort and sweat absorption but because Galot has a little disadvantage in washing and activity, we have considered about width or surplus in various parts of skirts and cautions during washing must be informed. Like this, in case when using Gal Cheon as the main material, a problem of management was raised but because workplaces per departments prioritizing images have answered very positively, it was believed that Gal Cheon uniform development has meaning. Also as persimmon juice is dyed on stretch fabrics, it was also believed to be good to secure functionality of fabrics. Like this, it was found out that it may be good to apply Gal Cheon to guest room departments which mainly affect images of hotels even though Gal Cheon has limits which must be overcome.

2. By considering harmony with Gal Cheon materials as impor- 
tant, mix techniques between materials found out in the trend survey were applied to the design. We have attempted color arrangement with materials such as chiffon which has mild and soft feel in order to harmonize with Gal Cheon which has solid feel. We have considered that we can distinct departments according to color arrangement at sleeve tips, placket of neckline, frill and ruffle. Because hotel employees would like to satisfy identity as well as individuality through uniforms, it is believed to be possible to satisfy individuality needs of one's own department while feeling sense of belonging to their hotels if uniforms with different feel under the same design are suggested.

3. As succeeding researches, response survey of the hotels and employees with newly developed uniforms must be implemented and more specific uniforms per departments and per seasons must be planned. Suggestion of a detailed design of uniforms per each department shall be considered too. Methods for differentiation of uniforms can be design and color pattern but it is believed to be possible to accomplish through materials as explained in this research. However, we need more specific reviews in order to overcome many limits unique to Gal Cheon. Today when tradition is considered as important, it is believed to be a good plan in informing tradition of Jeju and establishing images of hotels through uniforms by suggesting luxurious uniforms considering regional characteristics.

\section{Acknowledgement}

The research was supported by the 2014 scientific promotion program funded by Jeju National University.

\section{References}

Chung, G. Y. (2000). Hotel $\cdot$ Hospility $\cdot$ Marketing. Seoul: Younkyung munwhasa.

Hong, H. S. (2000). Product planning and design development for tourism product commercialization of Jeju Galot, small and medium corporations' technology development support center. Jeju National University, Jeju.

Horn, M. J., \& Gurel, L. M. (1981). The second skin-An interdisciplinary study of clothing. Boston: Houghton Mifflin Company.

Jeon, E. K., \& Kwon, S. H. (2000). Principle of pattern making. Seoul: Kyeomunsa.

Joseph,N.and Alex, N. (1990). The Uniform. A Sociological perspective. In. L.M. Gurel and Adornment $3^{\text {rd }}$, New York: Dubu Company.

Kang, H. W. (1995). The social psychology of clothing. Seoul: Kyeomunsa.

Ko, Y. K. (1982). A Groping for a new derection of Korean stewardess' uniform. Unpublished master's thesis,Ehwa Womans University, Seoul.

Laabs, J. J. (1995). Make sure your casual dress policy is nondiscriminary and jives with your corporate image. Journal of Personality, 24(6), 678-692.

Lee, H. R., Ha, I. J., \& Lee, J. J. (2003). The effect of hotel employee uniform on job satisfaction and service quality. Journal of the Tourism and Leisure Society, 15(1), 201-218

Lee, J. N., \& Park, O. L. (2007). A study on uniform satisfaction and preference of hotel employees. Journal of the Korean Data Analysis Society, 9(2),1229-2354.

Lee, K. H. (1991). A study on the uniform preference of the professional workers' uniform: Pointial on the bank in Pusan city. Unpublished master's thesis, Kyungsung University, Busan.

Lennon, S. J., \& Miller, F. G. (1984). Salience of physical appearance in impression formation. Home Economics Research Journal, 13(2), 95-103.

Lesile Davis Burns, Nancy O.Bryant (2002), The Business of Fashion(Lee Seon-Jae Trans.). Seoul: Hakmunsa. (Original work published 1998)

Nelson, K., \& Bowen, J. (2000). The effect of employee uniform on employee satisfaction. Cornell Hotel and Restaurant Administration Quarterly, April, 86-95.

Rafaeli, A., \& Pratt, M. G. (1993). Tailored meanings: On the meaning and impact of organizational dress. Academy of Management Review, 18(1), 32- 55.

Ryan, M. S. (1966). Clothing: A study in human behavior. NY: International Thomson Publishing.

Yang, L. N. (2001). A study on uniform satisfaction and preference of hotel employees in Korea. The Research Journal of Costume Culture, 9(5), 687-699.

'Standard size of 20s suggested in Size Korea' from http:// sizekorea.kats.go.kr/

'Fashion trend analysis during 2010 and 2015' HYPERLINK "http:// www.Fashionnetkorea.com" www.Fashionnetkorea.com

(Received 13 November 2014; 1st Revised 17 December 2014; 2nd Revised 19 December 2014; Accepted 25 December 2014)

Copyright (C) 2014 (by) the authors. This article is an open access article distributed under the terms and conditions of the Creative Commons Attribution license (http://creativecommons.org/licenses/by/3.0/), which permits unrestricted use, distribution, and reproduction in any medium, provided the original work is properly cited. 